\title{
DRAMATIC DECLINE OF ISCHAEMIC HEART DISEASE MORTALITY IN POST COMMUNIST CENTRAL EUROPE: RECOVERY FROM TOTALITY
}

\author{
Emil Ginter ${ }^{1}$, Vlado Simko² \\ ${ }^{1}$ Institute of Preventive and Clinical Medicine, Emeritus, Bratislava, Slovakia \\ ${ }^{2}$ State University New York, Downstate Medical Center at Brooklyn, USA
}

\begin{abstract}
SUMMARY
After 1970 the preexisting gap in population health between democratic Europe and communist countries became even more prominent. While in the democratic Europe there was a progressive rise in life expectancy associated with the decline in ischaemic heart disease (IHD), the trend on the other side of the iron curtain was exactly reverse. After the fall of communism in 1989 population health in the post-communist central Europe (CE) rapidly signalled a favourable recovery. This biphasic trend in post-communist countries is very remarkable. Most remarkably the decline in IHD mortality started soon after the demise of totality, even before the modernization of health care (new more effective medications and diagnostic technology), public campaign against smoking and improved supply of protective nutrients got chance to attain an important role. The decades-long psychosocial depression of communism was rapidly replaced with a promise of a better future. It is generally accepted that psychosocial factors are powerfool tools in the pathogenesis of IHD.
\end{abstract}

Key words: fall of communism, ischaemic heart disease, biphasic mortality in communist countries, psychosocial situation, modern health care, better nutrition, decline of smoking

Address for correspondence: E. Ginter, Račianska 17, 83102 Bratislava, Slovakia. E-mail: ginter.emil@mail.t-com.sk.

\section{INTRODUCTION}

The rapid downfall of the totality in 1989 had brought along the demise of deception, a powerful totalitarian instrument and the root cause of failure of one party rule. While the establishment thrived on the illusion of a science-based social order, in reality it was a relentless dictatorship excluding any checks and balances. The longer it endured, the more disastrous were the consequences. Not being able to keep pace with the economic, technological and social progress in the surrounding world, totality generated dire consequences for its subjugated population, not least regarding its health.

Very evident in comparison with democratic Europe was the gradual stagnation of life expectancy (LE), primarily related to incomparably higher IHD mortality (1). The main objective of this review is to address the mechanisms that induced an astonishingly rapid decline in IHD mortality in CE once the totalitarian system was overthrown. The data presented here is based mostly on reports of the World Health Organization Regional Office for Europe - European Health for All Database (2) and mortality indicators by 67 causes of death, age and sex (3) updated in July 2011. Regarding national statistics, most of the recent data for 2008-2009 originate from the Czech republic (CZ) (4, 5).

\section{Trends in Ischaemic Heart Disease Mortality}

The male IHD clearly stands out as the main component of the biphasic trend in CE countries (Fig. 1). Notably, in 1970 the IHD mortality in CE mirrored the mortality in Austria. After that year the IHD mortality in the communist CE started to rise very prominently. The fall of communism produced a dramatic decline in IHD. Female IHD had a similar although less prominent trend. The biphasic trend (pre and post communist IHD) is most remarkable at the age category 0-64 years. Population older than 65 , male and female, exhibited much less prominent difference. This leads to an interesting suggestion that the metabolic damage inflicted by previous decades was more pronounced in older people and unable to respond to beneficial effects of a new open society. Of the CE countries, Hungary is more difficult to evaluate because of trends of health disorders specific for this country (for example an extremely high cancer mortality). However, even Hungary experienced a decline in IHD in the later period after the fall of totality.

\section{DISCUSSION}

Heart disease has been one of the most heavily weighing causes of population disability, short life expectancy and high total mortality in communist CE. The paradigm of biphasic course of IHD mortality in CE, first a dramatic rise in 1970-1990, followed by an impressive decline after 1990, yields an important insight on how political and societal changes exert influence on population's well being. Similar but less prominent decline in coronary heart disease mortality ocurred also in most Western countries. It is believed that this is due to a decline in major cardiovascular risk factors (about 50\%) and also to improvement in disease management (approx. 40\%). 


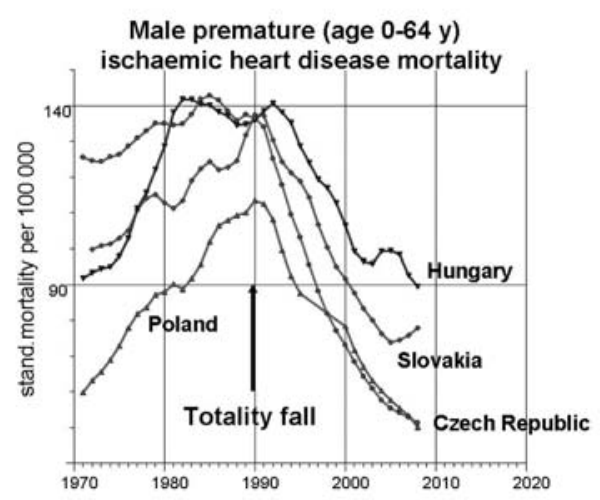

Fig.1. The premature male ischaemic heart disease (IHD) clearly stands out as the main component of the biphasic trends in CE countries (Poland, Czech Republic, Slovakia, Hungary) according to WHO (2).

\section{Psychosocial Factors}

This is a challenging and potentially controversial issue. The rapidity of decline in IHD mortality soon after the fall of communism in 1989, points out to other potential factors than modernization of health care. Notably, introduction of medications that were previously unaccessible, change in the life style, anti-smoking campaign and better nutrition, all these interventions require considerable time to exert population influence.

We suggest that psychosocial factors may have had a unique role in IHD epidemiology in the postcommunist CE. There is a plausible explanation that the sudden relief from the oppressive police regime, transition from totality to an open society and the perspective of a new and improved living standard brought along new perspectives with improved psychological awareness.

Psychosocial stress is associated with elevated levels of inflammatory markers, with higher concentration of IL-6 and C-reactive protein $(6,7)$. Different categories of emotional awareness may be associated with characteristic patterns of coagulation and fibrinolytic activity. All these suggest potential biobehavioural link to coronary artery disease $(8,9)$. A meta analysis of multiple studies documented evidence for an association between depression, social support, psychosocial characteristics and the pathogenesis and prognosis of IHD $(10,11)$. Presence of psychosocial stressors is associated with increased risk of acute myocardial infarction (12, 13). Another evidence is the data on subjective health perception of the population after demise of totality. Both men and women reported substantial improvement in their subjective health perception. Subjective well-being (SWB) is a significant predictor of mental health levels (14).

\section{The Role of Complex Medical Management}

Another very important mechanism potentially influencing the biphasic trend of IHD mortality in CE is the change in health care system. Motivation and skills of health personnel, accessibility of the most modern medications and medical devices were favourable factors contributing to changing patterns of health after 1989. However, these changes take time for gradual implementation. Health care system was in some regions of CE privatized with some best doctors who previously took refuge in administrative roles, returning to newly profitable patient care. The number of physicians per capita increased. The intensity of contacts with the representatives of health industry became comparable to the West.

Routine use of the angiotensin enzyme inhibitors in controlling the BP started to enter medical practice in the late 1970's. Yet it took much longer to popularize this in CE. There was a delay even in the preventive use of aspirin (15). Considerable risk of uncontrolled hypertension for IHD was appreciated only much later, especially after the introduction of inexpensive home monitoring pressure devices. Self-control of the BP revealed many new cases of masked hypertension, promoting early preventive management (16).

Decisive factor in controlling blood lipids and IHD was the massive introduction of cholesterol management with drugs (17, 18) in USA and in Western Europe. Still, this mode of lipid control including the statins (simvastatin, lovastatin) became widely applied in CE only in the mid 1990's. It took until the 2000's to introduce even more advanced interventions for serious complications of IHD: the thrombolytic therapy, percutaneous coronary diagnosis and intervention.

\section{The Role of Nutrition}

Improved intake of protective nutrients is another factor which might have played role in the decline of IHD mortality in post communist CE. Economic transformation and the free market brought along improved distribution of previously deficient vegetables and fruit. Food prices were restructured and previous consumption of animal sources of saturated fat and cholesterol decreased. The intake of plant-derived oil increased. Lowering consumption of saturated fat, including butter, has been documented to favourably affect the total and low density cholesterol (19).

High intake of red meat favours pathogenesis of IHD (20). Importantly, beef and pork, lard, eggs, and sugar consumption declined in CE, poultry products consumption increased. Hungary is an exception with persistently high consumption of pork and alcoholic beverages. Increased intake of vegetable has the benefit of bringing along protective unsaturated fatty acids, polyphenols and vitamins. Dietary cholesterol was partly replaced by plant sterols (21) and prevalence of chronic vitamin C deficiency decreased (22).

However, it took about 2-4 years of transition to market economy for these factors to influence population health. Nevertheless, in the same period fish consumption, an important source of protective n-3 fatty acids, did not substantially change (23). Data on alcohol consumption exhibit too much variability to be evaluated.

Longitudinal trends in major cardiovascular risk factors in the Czech population of randomly selected men and women aged 25-64 years were followed between 1985 and 2007/8 (24, 25). Over a period of 22-23 years, there was a significant decrease in the prevalence of smoking in males (from 45.0 to $30.5 \%$; $p<0.001$ ) but no change in smoking habits in females. Both systolic and diastolic blood pressure decreased significantly in both genders.

Despite a favourable drop in IHD mortality in CE after the fall of communism, IHD mortality remains in this part of Europe much higher than in Western Europe. Austria with high quality of health care and low IHD mortality is an important paradigm. If the 
present trend continues, the Czech Republic will reach Austrian medical success 25 years after the fall of totality. To reach such favourable health parameters will take in Poland cca 30 years, in Slovakia 35 years and in Hungary 40 years of life in democracy.

Regarding future trend of IHD in CE, new alarming signals are emerging. The Czech Republic now ranks among countries with high prevalence of obesity that is similar in men and women. It was proposed that this is associated with increasing consumption of pork, processed meat products and excessive beer drinking.

\section{CONCLUSION}

Last forty years witnessed a dramatic drop in IHD mortality in most of the democratic world. The IHD trend in formerly communist CE in 1970-1990 is markedly distinguished from the democratic world by an unprecedented deterioration in IHD and with stagnation in the life expectancy. Rapid improvement in IHD mortality after the fall of communism in $\mathrm{CE}$ further implicates the overall failure of the preceding regime.

Causes of a biphasic course in IHD mortality in Central Europe, decades of totality followed by return to democracy, are multifactorial. Certainly, unimpeded flow of information in an open society, direct access to medical innovations, modern medications (statins) and advanced diagnostics have been decisive in bringing improvement. Awareness of self care in people previously programmed to rely on the omnipresent central rule, promoted an active and more up-to-date prevention. The structure of nutrition substantially improved with less saturated fat and red meat. Increased intake of fruit and vegetables provided protective nutrients.

However, all these factors together cannot explain the rapid improvement in IHD mortality in the very first years after renewal of democracy. An interesting possibility is the influence of improved psychosocial environment. The adverse effect of continuing lack of perspective while surviving in the totalitarian regime probably contributed to the pathogenesis of IHD. The role of psychosocial impairment in IHD is now overwhelmingly recognized.

Overall enthusiasm from such unexpected improvement after the fall of communism has to be tempered by reports from $\mathrm{CE}$ of potential unwanted return of hypertension and diabetes, leading contributors to IHD. Obesity and diabetes type 2 epidemic have to be placed under control by consistent prevention. Populations that acquire a higher level of education are less prone to become obese (26).

\section{REFERENCES}

1. Ginter E, Simko V, Wsolova L. Fall of the iron curtain: male life expectancy in Slovakia, in the Czech Republic and in Europe. Cent Eur J Public Health. 2009 Dec;17(4):171-4.

2. European Health for All Database HFA-DB [Internet].Copenhagen: WHO Regional Office for Europe; c2011 [updated 2012 Jan; cited 2012 May 10]. Available from: http://data.euro.who.int/hfadb/.

3. European Mortality Database (MDB) [Internet]. Copenhagen: WHO Regional Office for Europe; c2011 [updated 2012 Jan; cited 2012 May 10]. Available from: http://data.euro.who.int/hfamdb/.

4. Institute of Health Information and Statistics of the Czech republic. Evaluation of health care in the Czech Republic after the year 1989. Prague: Institute of health information and statistics of Czech republic; 2010.
5. Czech Statistical Institute. Statistic Yearbook of Czech republic 2009. Prague: Czech Statistical Institute; 2010.

6. Ranjit N, Diez-Roux AV, Shea S, Cushman M, Seeman T, Jackson SA, et al. Psychosocial factors and inflammation in the multi-ethnic study of atherosclerosis. Arch Intern Med. 2007 Jan 22;167(2):174-81.

7. Pikhart H, Hubacek JA, Kubinova R, Nicholson A, Peasey A, Capkova N, et al. Depressive symptoms and levels of C-reactive protein: a populationbased study. Soc Psychiatry Psychiatr Epidemiol. 2009 Mar;44(3):217-22.

8. von Känel R, Mills PJ, Fainman C, Dimsdale JE. Effects of psychological stress and psychiatric disorders on blood coagulation and fibrinolysis: a biobehavioral pathway to coronary artery disease? Psychosom Med. 2001 Jul-Aug;63(4):531-44.

9. Hamer M, Molloy GJ, Stamatakis E. Psychological distress as a risk factor for cardiovascular events: pathophysiological and behavioral mechanisms. J Am Coll Cardiol. 2008 Dec 16;52(25):2156-62.

10. Kuper H, Marmot M, Hemingway H. Systematic review of prospective cohort studies of psychosocial factors in the etiology and prognosis of coronary heart disease. Semin Vasc Med. 2002 Aug;2(3):267-314.

11. Skala JA, Freedland KE, Carney RM. Coronary heart disease and depression: a review of recent mechanistic research. Can J Psychiatry. 2006 Oct;51(12):738-45.

12. Rosengren A, Hawken S, Ounpuu S, Sliwa K, Zubaid M, Almahmeed WA, et al.; INTERHEART investigators. Association of psychosocial risk factors with risk of acute myocardial infarction in 11119 cases and 13648 controls from 52 countries (the INTERHEART study): case-control study. Lancet. 2004 Sep 11-17;364(9438):953-62.

13. Nabi H, Shipley MJ, Vahtera J, Hall M, Korkeila J, Marmot MG, et al Effects of depressive symptoms and coronary heart disease and their interactive associations on mortality in middle-aged adults: the Whitehall II cohort study. Heart. 2010 Oct;96(20):1645-50.

14. Pavot W, Diener E. Review of the satisfaction with life scale. Psychol Assess. 1993;5(2): 164-72.

15. Razzouk L, Mathew V, Lennon RJ, Aneja A, Mozes JI, Wiste HJ, et al. Aspirin use is associated with an improved long-term survival in an unselected population presenting with unstable angina. Clin Cardiol. 2010 Sep;33(9):553-8.

16. Ogedegbe G, Agyemang C, Ravenell JE. Masked hypertension: evidence of the need to treat. Curr Hypertens Rep. 2010 Oct;12(5):349-55.

17. Mann D, Reynolds K, Smith D, Muntner P. Trends in statin use and lowdensity lipoprotein cholesterol levels among US adults: impact of the 2001 National Cholesterol Education Program guidelines. Ann Pharmacother. 2008 Sep;42(9):1208-15.

18. Ginter E, Simko V. Statins: the drugs for the 21st century? Bratisl Lek Listy. 2009;110(10):664-8.

19. Rioux V, Legrand P. Saturated fatty acids: simple molecular structure with complex cellular functions. Curr Opin Clin Nutr Metab Care. 2007 Nov; 10(6):752-8.

20. Bernstein AM, Sun Q, Hu FB, Stampfer MJ, Manson JE, Willett WC. Major dietary protein sources and risk of coronary heart disease in women. Circulation. 2010 Aug 31;122(9):876-83.

21. Padayatty SJ, Levine M. Fruit and vegetables: think variety, go ahead, eat! Am J Clin Nutr. 2008 Jan;87(1):5-7.

22. Ginter E. Vegetarian diets, chronic diseases and longevity. Bratisl Lek Listy. 2008;109(10):463-6.

23. He K, Song Y, Daviglus ML, Liu K, Van Horn L, Dyer AR, et al. Accumulated evidence on fish consumption and coronary heart disease mortality: a meta-analysis of cohort studies. Circulation. 2004 Jun 8;109(22):2705-11.

24. Cífková R, Skodová Z, Bruthans J, Adámková V, Jozífová M, Galovcová $\mathrm{M}$, et al. Longitudinal trends in major cardiovascular risk factors in the Czech population between 1985 and 2007/8. Czech MONICA and Czech post-MONICA. Atherosclerosis. 2010 Aug;211(2):676-81.

25. Cífková R, Skodová Z, Bruthans J, Holub J, Adámková V, Jozífová M, et al. Longitudinal trends in cardiovascular mortality and blood pressure levels, prevalence, awareness, treatment, and control of hypertension in the Czech population from 1985 to 2007/2008. J Hypertens. 2010 Nov;28(11):2196-203.

26. Hajat A, Kaufman JS, Rose KM, Siddiqi A, Thomas JC. Do the wealthy have a health advantage? Cardiovascular disease risk factors and wealth. Soc Sci Med. 2010 Dec;71(11):1935-4.

Received December 11, 2010 Accepted in revised form February 27, 2012 